\title{
Bias correction of a gauge-based gridded product to improve extreme precipitation analysis in the Yarlung Tsangpo-Brahmaputra River basin
}

\author{
Xian Luo ${ }^{1,2}$, Xuemei Fan ${ }^{1}$, Yungang $\mathrm{Li}^{1,2}$, and Xuan $\mathbf{J i}^{1,2}$ \\ ${ }^{1}$ Institute of International Rivers and Eco-security, Yunnan University, Kunming, China \\ ${ }^{2}$ Yunnan Key Laboratory of International Rivers and Transboundary Eco-security, Kunming, China
}

Correspondence: Xian Luo (luoxian@ynu.edu.cn) and Yungang Li (ygli@ynu.edu.cn)

Received: 3 October 2019 - Discussion started: 22 October 2019

Revised: 14 May 2020 - Accepted: 23 June 2020 - Published: 17 August 2020

\begin{abstract}
Critical gaps in the amount, quality, consistency, availability, and spatial distribution of rainfall data limit extreme precipitation analysis, and the application of gridded precipitation data is challenging because of their considerable biases. This study corrected Asian Precipitation Highly Resolved Observational Data Integration Towards Evaluation of Water Resources (APHRODITE) estimates in the Yarlung Tsangpo-Brahmaputra River basin (YBRB) using two linear and two nonlinear methods, and their influence on extreme precipitation indices was assessed by crossvalidation. Bias correction greatly improved the performance of extreme precipitation analysis. The ability of four methods to correct wet-day frequency and coefficient of variation were substantially different, leading to considerable differences in extreme precipitation indices. Local intensity scaling (LOCI) and quantile-quantile mapping (QM) performed better than linear scaling (LS) and power transformation (PT). This study would provide a reference for using gridded precipitation data in extreme precipitation analysis and selecting a bias-corrected method for rainfall products in datasparse regions.
\end{abstract}

\section{Introduction}

Extreme precipitation often leads to floods, debris flows, and other secondary disasters (Wang et al., 2017), and changes in the frequency and intensity of extreme precipitation profoundly influence both the natural environment and human society (Easterling et al., 2000; Yucel and Onen, 2014). Rain- fall observations provide a primary foundation for comprehending their long-term variability and change in extreme precipitation (Alexander, 2016). Accurate rainfall data are necessary for flood protection and water resource management. However, due to scarce spatial coverage of rainfall stations, short-length rainfall records, and high proportions of missing data, observations currently available in some remote basins are clearly inadequate to capture their precipitation characteristics. In addition, observed rainfall data are usually difficult to collect in international river basins because many countries may not share or freely distribute data (Lakshmi et al., 2018).

The Yarlung Tsangpo-Brahmaputra River is the fourthlargest river in the world in terms of flow (Kamal-Heikman et al., 2007) and is influenced profoundly by complex atmospheric dynamics and regional climate processes (Immerzeel et al., 2010; Pervez and Henebry, 2015). Because its agriculture and economy rely heavily on monsoon precipitation, the basin is particularly vulnerable to changing climate (Singh et al., 2016; Liu et al., 2018; Janes et al., 2019; Xu et al., 2019; Zhang et al., 2019). During the four summer monsoon months of June, July, August, and September (JJAS), extreme precipitation with large uncertainties leads to numerous floods (Kamal-Heikman et al., 2007; Dimri et al., 2016; Malik et al., 2016). However, understanding of extreme precipitation in the Yarlung Tsangpo-Brahmaputra River basin (YBRB) has a number of gaps because of its complex topographical interactions with atmospheric flows, lack of observations, and data-sharing issues, which hinder effective flood management (Ray et al., 2015; Prakash et al., 2019). 
Currently, different gridded rainfall products provide effective information over regional to global scales, which could be broadly classified into four categories: (1) gaugebased datasets that build on observations from rainfall stations, (2) products from numerical weather predictions or atmospheric models, (3) satellite-only products, and (4) combined satellite-gauge products. The performance of these products varies from region to region (Duan et al., 2016). Given the heterogeneity of orography and climate in the YBRB, observing and modeling its precipitation are very challenging (Khandu et al., 2017). In addition, satellite products are less reliable because high convective rainfall generally takes place in the southern foothills of the Himalayas (Prakash et al., 2015). Compared with some other gaugebased products, the Asian Precipitation Highly Resolved Observational Data Integration Towards Evaluation of Water Resources (APHRODITE) dataset collected more rainfall observations across South Asia (Rana et al., 2015), which have been proven to better estimate spatial precipitation (Andermann et al., 2011). Nonetheless, the lack (and uneven distribution) of rainfall stations at high altitudes in the Tibetan Plateau and Himalayas may introduce uncertainty and affect the accuracy of APHRODITE estimates (Rana et al., 2015; Chaudhary et al., 2017).

Numerous rainfall observations can be obtained from public databases, although their short record and static character limit their direct application in precipitation analysis (Donat et al., 2013). However, these data could be useful for bias correction of gauge-based gridded products by providing additional observations from the denser network of rainfall stations. On the other hand, several methods have been developed to adjust global climate model (GCM) data, ranging from simple linear scaling to more sophisticated nonlinear approaches (Teutschbein and Seibert, 2012). Similarly, these bias-correction methods could be applied to correct gridded rainfall products in sparsely gauged mountainous basins ( $\mathrm{He}$ et al., 2017). It is important to study whether extreme precipitation analysis could be improved by bias correction of gridded precipitation data and how different methods would influence extreme precipitation indices.

This study evaluated different bias-correction approaches for APHRODITE estimates in the YBRB and assessed their effects on extreme precipitation analysis. We first corrected APHRODITE estimates by both linear and nonlinear methods. Next, we calculated extreme precipitation indices using the original and differently corrected APHRODITE estimates, and the effects of bias correction on extreme precipitation analysis were further investigated by cross-validation. The results provide support to the application of gridded precipitation data and bias-corrected methods in extreme precipitation analysis.

\section{Material and methods}

\subsection{Study area}

The YBRB can be divided into three physiographic zones: (1) the Tibetan Plateau (TP), covering $44.4 \%$ of the basin, with elevations above $3500 \mathrm{~m}$; (2) the Himalayan belt (HB), accounting for $28.6 \%$ of the basin, with elevations ranging from 100 to $3500 \mathrm{~m}$; and (3) the floodplains (FP), covering $27.0 \%$ of the basin, with elevations up to $100 \mathrm{~m}$ (Immerzeel, 2008).

The moisture in the YBRB is mainly from the Indian Ocean. The YBRB exhibits a broad range of precipitation from the semiarid upstream areas to the HB characterized by abundant orographic rainfall and the vast humid FP. In the upstream areas, precipitation is concentrated during JJAS, and rainfall intensity is mostly low due to long-distance moisture transport (Guan et al., 1984). The irregular topographic variations in the Himalayas profoundly affect the spatial distribution of precipitation by altering monsoonal flow, producing intense orographic rainfall along the $\mathrm{Hi}-$ malayan foothills (Khandu et al., 2017). The downstream areas also receive high rainfall from monsoon flow during JJAS, accounting for $60 \%-70 \%$ of the annual rainfall (Gain et al., 2011).

\subsection{Data sources}

\subsubsection{Observational data}

In the upper YBRB, rainfall data across China recorded at 31 meteorological stations were collected from the National Meteorological Information Center (NMIC, sourced from the China Meteorological Data Sharing Service System). In addition, data observed at 91 rainfall stations in the downstream area were obtained from the Global Historical Climatology Network (GHCN)-Daily dataset for bias correction. The GHCN-Daily dataset comprises observations from four sources, which have been undergone extensive quality reviews, including the U.S. Collection, the International Collection, the Government Exchange Data, and the Global Summary of the Day. The locations of rainfall stations are shown in Fig. 1.

\subsubsection{APHRODITE estimates}

Numerous rainfall observations were incorporated into APHRODITE estimates, including (1) Global Telecommunication System (GTS)-based data, (2) data obtained from other projects or organizations, and (3) their own collection. The rainfall observations that had undergone quality control were gathered, and the ratios of rainfall observations to the world climatology were calculated and then interpolated for each month. The interpolated ratios were multiplied by the world climatology, and the first six components of the fast 


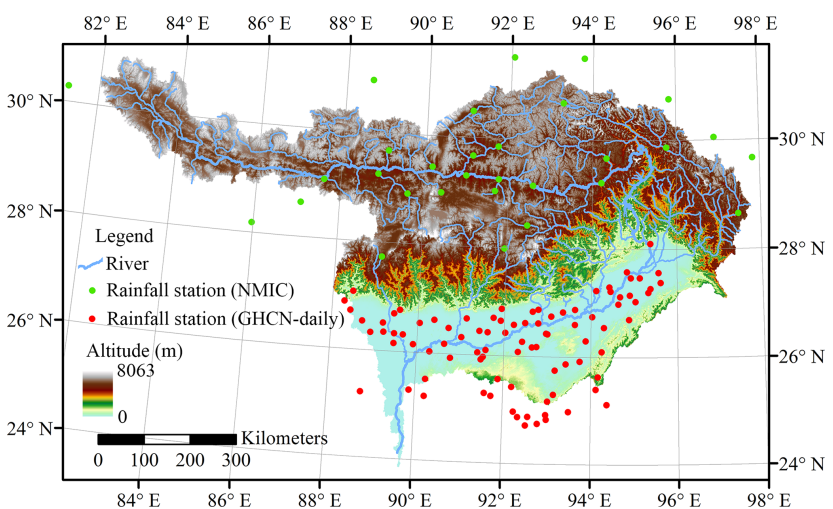

Figure 1. Locations of rainfall stations in the Yarlung TsangpoBrahmaputra River basin (YBRB).

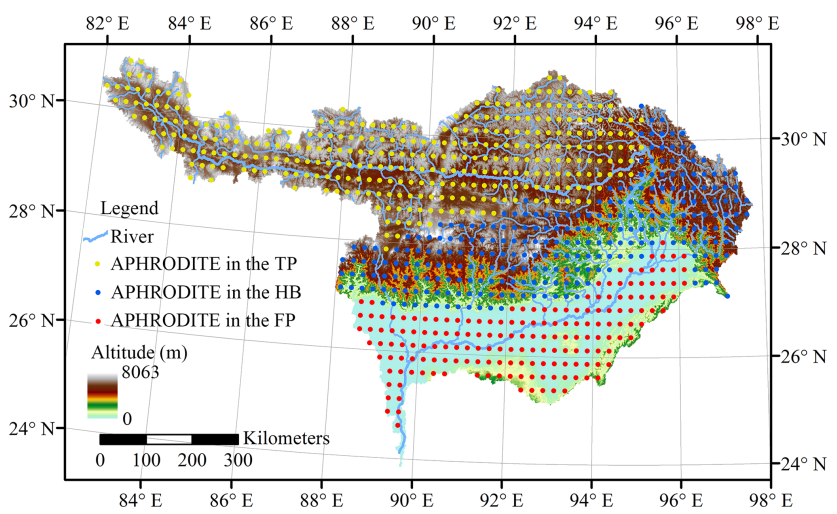

Figure 2. Location of Asian Precipitation Highly Resolved Observational Data Integration Towards Evaluation of Water Resources (APHRODITE) grids over the Tibetan Plateau (TP), Himalayan belt (HB), and floodplains (FP).

Fourier transform of the resulting values were used to obtain daily precipitation (Yatagai et al., 2012).

Daily rainfall data of APHRO_MA_025deg_V1101 (http://aphrodite.st.hirosaki-u.ac.jp/index.html, last access: 13 August 2020) at $0.25^{\circ}$ resolution in the Asian monsoon area end in 2007, while recently published APHRO_MA_025deg_V1101EX_R1 (http://aphrodite.st.hirosaki-u.ac.jp/index.html, last access: 13 August 2020), using the same algorithm and spatial resolution, extend the time series over the period 2007-2015. Therefore, extreme precipitation could be analyzed from the period 1951-2015 by applying both datasets. To investigate the influence of topography on bias-corrected APHRODITE estimates, the grids were classified into three topographic zones (the TP, HB, and FP; Fig. 2).

\subsection{Methods}

\subsubsection{Bias-correction methods}

Two linear methods (linear scaling, LS, and local intensity scaling, LOCI) and two nonlinear methods (power transformation, PT, and quantile-quantile mapping, QM) were used for bias correction in this study.

\section{(1) LS}

LS corrects monthly estimates in accordance with observations (Lenderink et al., 2007). It corrects APHRODITE estimates using the ratio between mean monthly observation and corresponding estimation:

$P_{\mathrm{APH}}^{*}(d)=P_{\mathrm{APH}}(d) \cdot\left[\frac{\mu_{\mathrm{m}}\left(P_{\mathrm{obs}}(d)\right)}{\mu_{\mathrm{m}}\left(P_{\mathrm{APH}}(d)\right)}\right]$,

where $P_{\mathrm{APH}}^{*}(d)$ and $P_{\mathrm{APH}}(d)$ are the daily precipitation of the corrected and original APHRODITE estimates, respectively, and $P_{\mathrm{obs}}(d)$ is the daily precipitation observed at the rainfall station in corresponding grid of the APHRODITE estimate. $\mu_{\mathrm{m}}\left(P_{\mathrm{obs}}(d)\right)$ and $\mu_{\mathrm{m}}\left(P_{\mathrm{APH}}(d)\right)$ are the mean monthly precipitation of observations and corresponding APHRODITE estimates in the $m$ th month, respectively.

\section{(2) LOCI}

LOCI makes a flexible adjustment to the wet-day frequency and intensity (Schmidli et al., 2006; Teutschbein and Seibert, 2012). Firstly, an adjusted precipitation threshold ( $\left.P_{\text {th }}, \mathrm{APH}\right)$ is determined so that the number of days exceeding this threshold for APHRODITE estimates matches that of observed days with precipitation larger than $0 \mathrm{~mm}$. Secondly, a linear scaling factor $(s)$ for wet days is computed:

$s=\frac{\mu_{\mathrm{m}}\left(P_{\mathrm{obs}}(d) \mid P_{\mathrm{obs}}(d)>0 \mathrm{~mm}\right)}{\mu_{\mathrm{m}}\left(P_{\mathrm{APH}}(d) \mid P_{\mathrm{APH}}(d)>P_{\mathrm{th}, \mathrm{APH}}\right)-P_{\mathrm{th}, \mathrm{APH}}}$,

where $\mu_{\mathrm{m}}\left(P_{\mathrm{obs}}(d) \mid P_{\mathrm{obs}}(d)>0 \mathrm{~mm}\right)$ is the mean monthly precipitation of observations with daily precipitation larger than $0 \mathrm{~mm}$ and $\mu_{\mathrm{m}}\left(P_{\mathrm{APH}}(d) \mid P_{\mathrm{APH}}(d)>P_{\mathrm{th}}, \mathrm{APH}\right)$ is the mean monthly precipitation of APHRODITE estimates with daily precipitation larger than $P_{\mathrm{th}}$, APH. Finally, the precipitation data are corrected using

$P_{\mathrm{APH}}^{*}(d)=\max \left(s \cdot\left(P_{\mathrm{APH}}(d)-P_{\mathrm{th}, \mathrm{APH}}\right), 0\right)$.

(3) PT

PT corrects both the mean and the coefficient of variation in precipitation (Leander and Buishand, 2007), changing precipitation by

$P_{\mathrm{APH}}^{*}(d)=a \cdot\left(P_{\mathrm{APH}}(d)\right)^{b}$,

where $a$ and $b$ are the parameters of the power transformation, which are obtained using a distribution-free approach 
and estimated for each month within a $90 \mathrm{~d}$ window. Using a root-finding algorithm, the value of $b$ is firstly determined to ensure that the coefficient of variation in the corrected estimates matches that of the observations. The parameter $a$ is then calculated using the mean observation and the corresponding mean of the transformed values.

\section{(4) QM}

By shifting occurrence distributions, QM corrects the distribution function of precipitation estimates to match that of observations, which is commonly used in correcting systematic distributional biases (Cannon et al., 2015). A gamma distribution is usually assumed for precipitation events (Teutschbein and Seibert, 2012):

$f_{\gamma}(x \mid \alpha, \beta)=x^{\alpha-1} \cdot \frac{1}{\beta^{\alpha} \cdot \Gamma(\alpha)} \cdot e^{-\frac{x}{\beta}} ; x \geq 0 ; \alpha, \beta>0$,

where $\alpha$ and $\beta$ are the shape parameter and scale parameter, respectively.

The cumulative density function (CDF) of the APHRODITE estimates is adjusted to agree with that of the observation, and the daily precipitation for APHRODITE estimates is corrected depending on its quantile. It should be noted that for APHRODITE estimates, many days had low precipitation estimates instead of substantial dry conditions, which may distort the distribution of daily precipitation. Therefore, an adjusted precipitation threshold is also used to ensure the wet-day frequency of corrected APHRODITE estimates match the observed frequency.

$P_{\mathrm{APH}}^{*}(d)=$

$\left\{\begin{array}{l}0, \text { if } P_{\mathrm{APH}}(d)<P_{\mathrm{th}, \mathrm{APH}} \\ F_{\gamma}^{-1}\left(F_{\gamma}\left(P_{\mathrm{APH}}(d) \mid \alpha_{\mathrm{APH}, \mathrm{m}}, \beta_{\mathrm{APH}, \mathrm{m}}\right) \mid \alpha_{\mathrm{obs}, \mathrm{m}}, \beta_{\mathrm{obs}, \mathrm{m}}\right),\end{array}\right.$

otherwise

$F_{\gamma}$ and $F_{\gamma}^{-1}$ are the gamma CDF and its inverse, respectively. $\alpha_{\mathrm{APH}, \mathrm{m}}$ and $\beta_{\mathrm{APH}, \mathrm{m}}$ are the shape parameter and scale parameter of the original APHRODITE estimates in the $m$ th month, respectively, and $\alpha_{\mathrm{obs}, \mathrm{m}}$ and $\beta_{\mathrm{obs}, \mathrm{m}}$ are those of observations in the $m$ th month, respectively.

This study corrected the grids of the APHRODITE estimates that contained time series of observations, and the parameters of bias correction were determined using corresponding available rainfall observations. After that, the APHRODITE estimates from 1951 to 2015 in these grids were corrected by four bias-correction methods. Hereafter, APHRODITE estimates corrected by LS, LOCI, PT, and QM are referred as LS-APHRODITE, LOCI-APHRODITE, PTAPHRODITE, and QM-APHRODITE estimates.

\subsubsection{Indices of extreme precipitation}

To characterize extreme precipitation during JJAS, six indices recommended by the Expert Team on Climate Change
Detection and Indices (ETCCDI), including consecutive wet days (CWD), number of heavy precipitation days (R10mm), number of very heavy precipitation days (R20mm), maximum $1 \mathrm{~d}$ precipitation amount $(\mathrm{Rx} 1 \mathrm{~d})$, maximum $5 \mathrm{~d}$ precipitation amount (Rx5d), and simple daily intensity index (SDII), were applied in this study. Detailed descriptions of these indices are shown in Table 1. The indices fall roughly into three categories: (1) duration indices, which represent the length of the wet spell; (2) threshold indices, which count the days on which a fixed precipitation threshold is exceeded; and (3) absolute indices, which describe the maximum 1 or $5 \mathrm{~d}$ precipitation amount (Sillmann et al., 2013).

Extreme precipitation indices were calculated for corrected APHRODITE estimates in the grids distributed with rainfall stations. To obtain extreme precipitation indices in other grids, inverse distance weighted (IDW) interpolation for extreme precipitation indices were performed. This allowed us to calculate mean values for each of the three topographic zones.

\subsubsection{Validation on bias correction}

Cross-validation was applied to evaluate the performance of four bias-correction methods. At each rainfall station, the observations were divided into two groups. Two-thirds of the rainfall records were applied to calculate the parameters of LS, LOCI, PT, and QM, respectively. Making use of these parameters, the APHRODITE estimates were then corrected. The mean error (ME) between the extreme precipitation indices obtained from the corrected APHRODITE estimates and those obtained from the remaining third of the rainfall observations were calculated to evaluate the performance of different bias-correction methods.

\section{Results}

\subsection{Evaluation of extreme precipitation indices}

The ME of extreme precipitation indices during JJAS for validation are shown in Fig. 3. For the original APHRODITE estimates, the MEs of CWD in the TP, HB, and FP were $8.3,16.4$, and $21.8 \mathrm{~d}$, respectively. There were a lot of days with low precipitation estimations instead of substantial dry conditions, leading to the overestimation of CWD. Likewise, this propagated to LS-APHRODITE estimates with similar MEs of CWD, because there was no change made to the wetday frequency. The MEs of CWD in the TP, HB, and FP for LOCI-APHRODITE estimates were 3.1, 1.2, and $1.4 \mathrm{~d}$, respectively, and those for QM-APHRODITE estimates were 2.5, 0.8, and $0.9 \mathrm{~d}$, respectively. For both LOCI- and QMAPHRODITE estimates, the days with low precipitation estimations instead of substantial dry conditions were redefined as dry days using the precipitation threshold, resulting in much lower ME and more reliable CWD. Finally, although PT did not directly correct wet-day frequency, the CWD for 
Table 1. Detailed description of extreme precipitation indices.

\begin{tabular}{llll}
\hline Index & Descriptive name & Definition & Unit \\
\hline CWD & Consecutive wet days & $\begin{array}{l}\text { Maximum number of consecutive days with precipita- } \\
\text { tion } \geq 1 \mathrm{~mm}\end{array}$ & days \\
\hline R10mm & Number of heavy precipitation days & $\begin{array}{l}\text { Count of days when precipitation } \geq 10 \text { mm during June, } \\
\text { July, August, and September (JJAS) }\end{array}$ & days \\
\hline R20mm & Number of very heavy precipitation days & Count of days when precipitation $\geq 20$ mm during JJAS & days \\
\hline Rx1d & Maximum 1 d precipitation amount & Maximum 1 d precipitation & mm \\
\hline Rx5d & Maximum 5 d precipitation amount & Maximum consecutive 5 d precipitation & mm \\
\hline SDII & Simple daily intensity index & $\begin{array}{l}\text { Total precipitation during JJAS divided by the number } \\
\text { of wet days (when precipitation } \geq 1 \text { mm) }\end{array}$ & mm d \\
\hline
\end{tabular}

PT-APHRODITE estimates were lower than those for the original APHRODITE estimates because very low precipitation was corrected.

The original APHRODITE data tended to underestimate heavy and very heavy precipitation days. Bias correction reduced error in R10mm and R20mm, except for LS, and the absolute values of ME for LOCI-, PT-, and QMAPHRODITE estimates were mostly lower than $1.0 \mathrm{~d}$. LOCI, PT, and QM are able to effectively correct heavy and very heavy precipitation days.

For the original APHRODITE estimates, the MEs of Rx1d were $-11.3,-89.1$, and $-50.5 \mathrm{~mm}$ in the TP, HB, and FP, respectively, and those of $\mathrm{Rx} 5 \mathrm{~d}$ reached $-18.0,-167.4$, and $-76.8 \mathrm{~mm}$, respectively. The original APHRODITE estimates greatly underestimated Rx1d and Rx5d. For the corrected APHRODITE estimates, QM performed best on Rx1d, and the MEs for QM-APHRODITE estimates were -0.1, -1.9 , and $-5.4 \mathrm{~mm}$, respectively. LS and LOCI used a consistent ratio in linear transformation, resulting in underestimation of Rx1d. In addition, LOCI outperformed other methods for Rx5d, and the overestimation in the HB and FP for PT- and QM-APHRODITE estimates was greater.

The MEs of SDII for the original APHRODITE estimates in the TP, HB, and FP were $-2.4,-13.9$, and $-11.0 \mathrm{~mm}$, respectively. Firstly, heavy and very heavy precipitation in the HB and TP were not fully captured by the original APHRODITE estimates. Secondly, the original APHRODITE estimates overestimated wet days, which distorted the estimation of precipitation intensity. Smaller errors were found in LOCI- and QM-APHRODITE estimates because they corrected rainfall amount and the number of rainy days.

\subsection{Extreme precipitation indices calculated from the original and corrected APHRODITE estimates}

\subsubsection{Extreme precipitation indices in the three physiographic zones}

Extreme precipitation indices calculated from the original APHRODITE estimates and four corrected APHRODITE estimates in the three different physiographic zones are shown in Fig. 4. The CWD estimated using the original APHRODITE and LS-APHRODITE estimates were similar. Meanwhile, those derived from LOCI-, PT-, and QMAPHRODITE estimates were much lower.

Mean R10mm during JJAS obtained by the original APHRODITE estimates in the TP, HB, and FP were 6.7, 31.0 , and $47.7 \mathrm{~d}$, respectively. These were similar to those estimated by corrected APHRODITE estimates. However, the differences in R20mm were much more pronounced. Mean $\mathrm{R} 20 \mathrm{~mm}$ in $\mathrm{HB}$ and FP for bias-corrected APHRODITE datasets was close to 19.0 and $26.5 \mathrm{~d}$, respectively, which is approximately $4-5 \mathrm{~d}$ higher than those derived from the original APHRODITE estimates.

Compared with the original APHRODITE estimates, the Rx1d and Rx5d increased greatly after bias correction. In the $\mathrm{HB}$, the mean Rx1d obtained from the original APHRODITE estimates was $49.5 \mathrm{~mm}$, while those for LS-, LOCI-, PT-, and QM-APHRODITE estimates were 72.4, 90.1, 109.0, and $103.8 \mathrm{~mm}$, respectively. In addition, the ranges of Rx1d and $\mathrm{Rx} 5 \mathrm{~d}$ also increased considerably.

The differences in SDII between the original and corrected APHRODITE estimates were also marked. For example, mean SDII in the FP calculated from the original APHRODITE estimates was $13.4 \mathrm{~mm}$. After correction, mean SDII for LOCI- and QM-APHRODITE estimates increased to 23.4 and $25.1 \mathrm{~mm}$, respectively. These values were much greater than those derived from LS- and PTAPHRODITE datasets (15.7 and $17.7 \mathrm{~mm}$ ). 

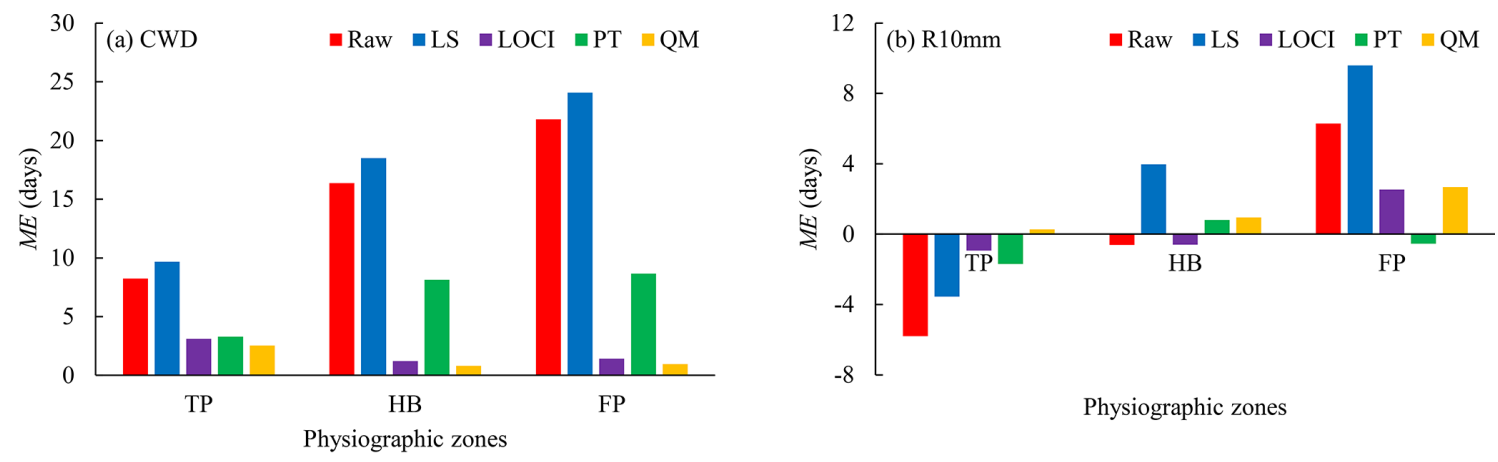

Physiographic zones
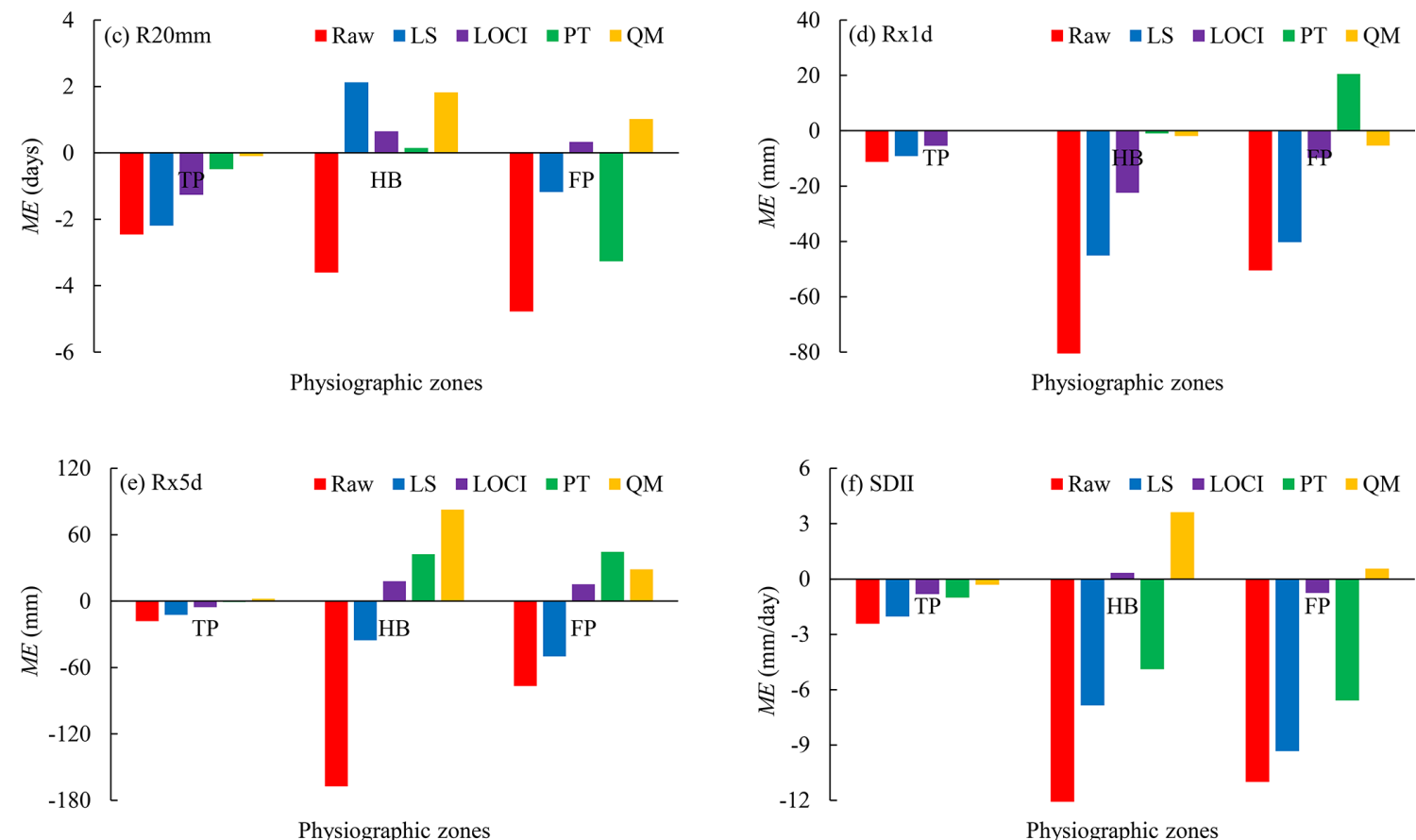

Figure 3. Mean error (ME) of (a) consecutive wet days (CWD), (b) number of heavy precipitation days (R10mm), (c) number of very heavy precipitation days $(\mathrm{R} 20 \mathrm{~mm})$, (d) maximum $1 \mathrm{~d}$ precipitation amount (Rx1d), (e) maximum $5 \mathrm{~d}$ precipitation amount (Rx5d), and (f) simple daily intensity index (SDII) during June, July, August, and September (JJAS) for validation in the three different physiographic zones (TP, $\mathrm{HB}$, and FP) of the YBRB.

\subsubsection{Relative changes in extreme precipitation indices}

The relative changes in extreme precipitation indices during JJAS based on the original and corrected APHRODITE estimates are shown in Fig. 5. The CWD for LOCI-, PT-, and QM-APHRODITE estimates were all lower than the original APHRODITE estimates, yielding relative change rates from $-66 \%$ to $-27 \%$. Bias correction decreased the number of rainy days except when using LS. The variations in R10mm and R20mm illustrated that corrected APHRODITE estimates identified much more extreme precipitation events in the TP. The changes in indices varied considerably for different correction methods, with the change rates of R20mm in the TP for LS-, LOCI-, PT-, and QM-APHRODITE estimates being $30.4 \%, 169.2 \%, 297.1 \%$, and $317.4 \%$, respec- tively. For Rx1d, Rx5d, and SDII, the increases in the HB were much pronounced than those in the FP and TP. Except for the LS-APHRODITE estimates, the increases in Rx1d and $\mathrm{Rx} 5 \mathrm{~d}$ in the HB were all above $70 \%$ for the corrected APHRODITE estimates.

\subsection{Influence of bias correction on the spatial distribution of extreme precipitation indices}

Rainstorms over the lower YBRB usually have a duration of 2-3d (Dhar and Nandargi, 2000), and large multiday precipitation events are crucial to the floods in the basin. Hence, the spatial distribution of Rx5d during JJAS based on the original APHRODITE estimates was compared with corrected APHRODITE estimates in Fig. 6. For the origi- 

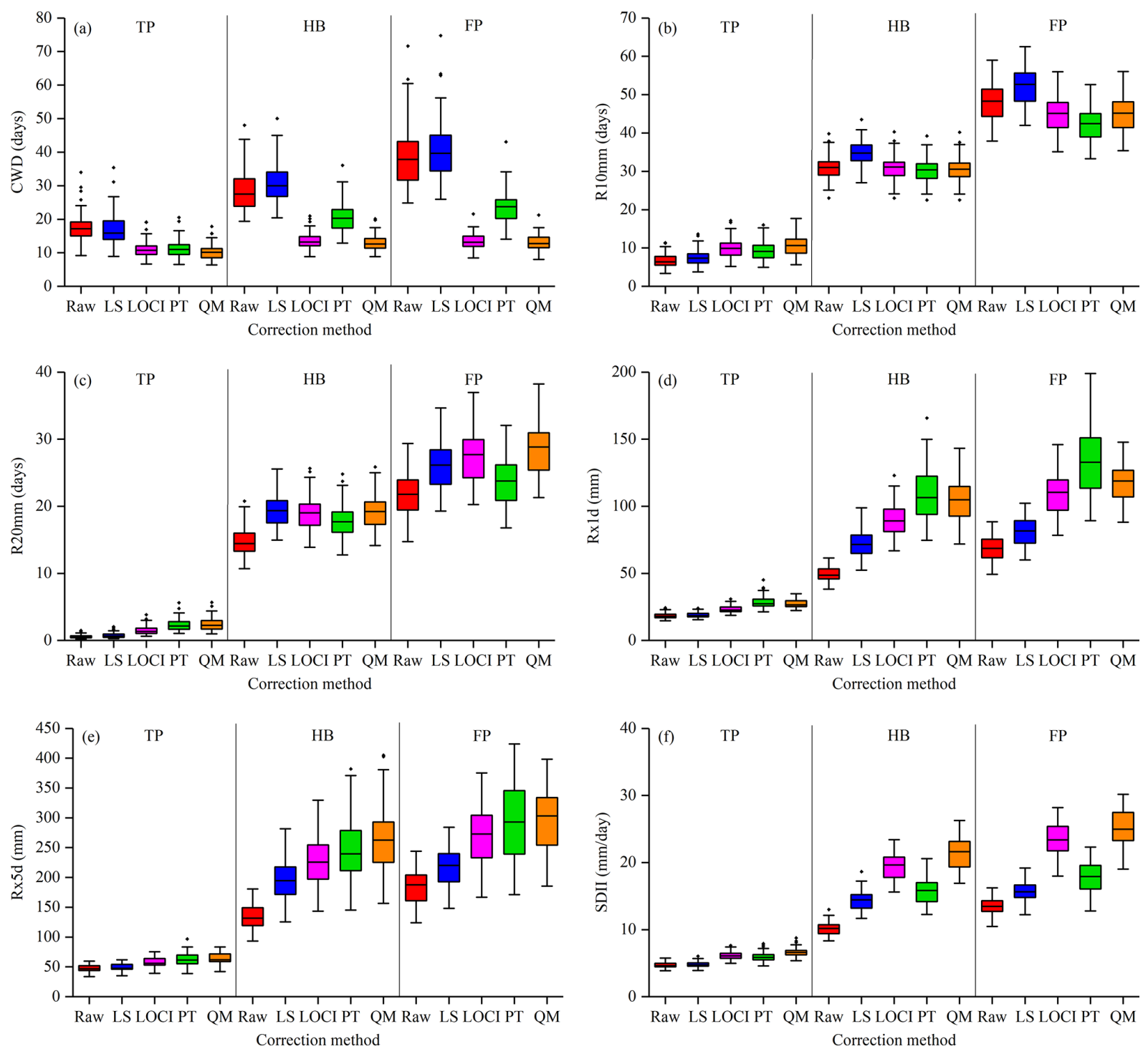

Figure 4. Box and whisker plot for (a) CWD, (b) R10mm, (c) R20mm, (d) Rx1d, (e) Rx5d, and (f) SDII during JJAS in the three different physiographic zones (the TP, HB, and FP) of the YBRB derived from the original and corrected APHRODITE estimates.

nal APHRODITE estimates, the area with Rx5d higher than $300 \mathrm{~mm}$ only accounted for $2.0 \%$ of the basin, while the proportions for LS-, LOCI-, PT-, and QM-APHRODITE estimates were $10.9 \%, 18.7 \%, 21.7 \%$, and $21.3 \%$, respectively. The most profound difference between the original and corrected APHRODITE estimates occurred over the windward slopes of the Himalayas before the river flows into the Brahmaputra valley. The Rx5d calculated from the original APHRODITE estimates was lower than $300 \mathrm{~mm}$, while much higher Rx5d was obtained after bias correction, yielding maxima of 946.6, 1030.3, 1105.1, and $1396.6 \mathrm{~mm}$ for LS-, LOCI-, PT-, and QM-APHRODITE estimates, respectively. The eastern Himalayas, acting as orographic barriers, push the southwest moist air upwards, leading to heavier extreme precipitation over the windward slopes (Singh et al., 2004; Bookhagen and Burbank, 2010; Dimri et al., 2016). However, the original APHRODITE estimates tended to substantially underestimate this extreme precipitation. Besides the aforementioned region, higher $\mathrm{Rx} 5 \mathrm{~d}$ along the $\mathrm{Hi}$ malayan front was also found after bias correction. In this case, extreme precipitation calculated from nonlinear approaches was heavier than that derived from linear methods. In general, bias correction is able to consider topographic effects on the spatial distribution of extreme precipitation more comprehensively.

\section{Discussion}

Using two linear and two nonlinear bias methods, we corrected APHRODITE estimates during JJAS in the YBRB to 

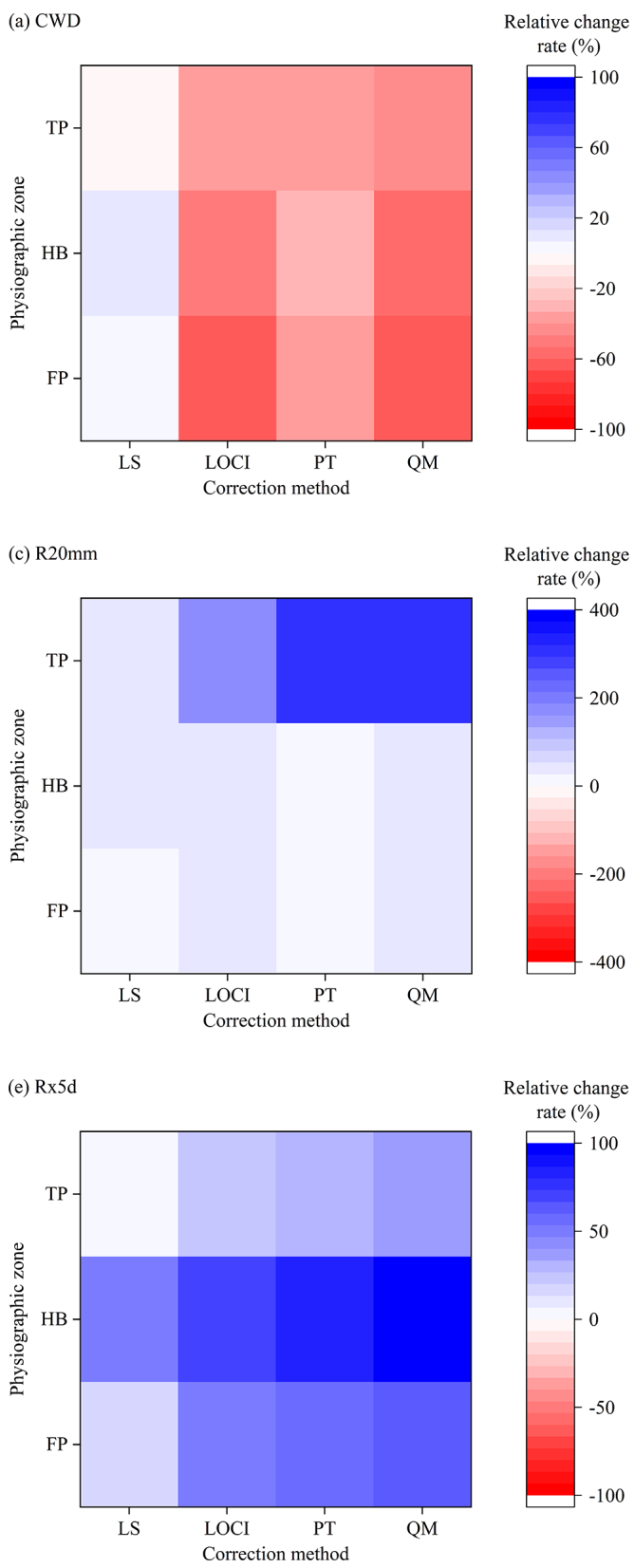

Figure 5. Relative change rate of (a) CWD, (b) R10mm, (c) R20mm corrected APHRODITE estimates.

investigate the effects of different approaches on extreme precipitation analysis. Extreme precipitation indices were strongly dependent on the bias-correction approach applied.

A primary problem when using gauge-based gridded datasets for extreme precipitation analysis is the fundamental mismatch between point-based observations and gridded estimates (Alexander, 2016). In addition, the spatial coverage of rainfall stations is another major source of uncertainty, particularly where spatial distributions of precipitation are complex (Donat et al., 2013). There are currently several approaches for bias correction, ranging from simple linear scal-
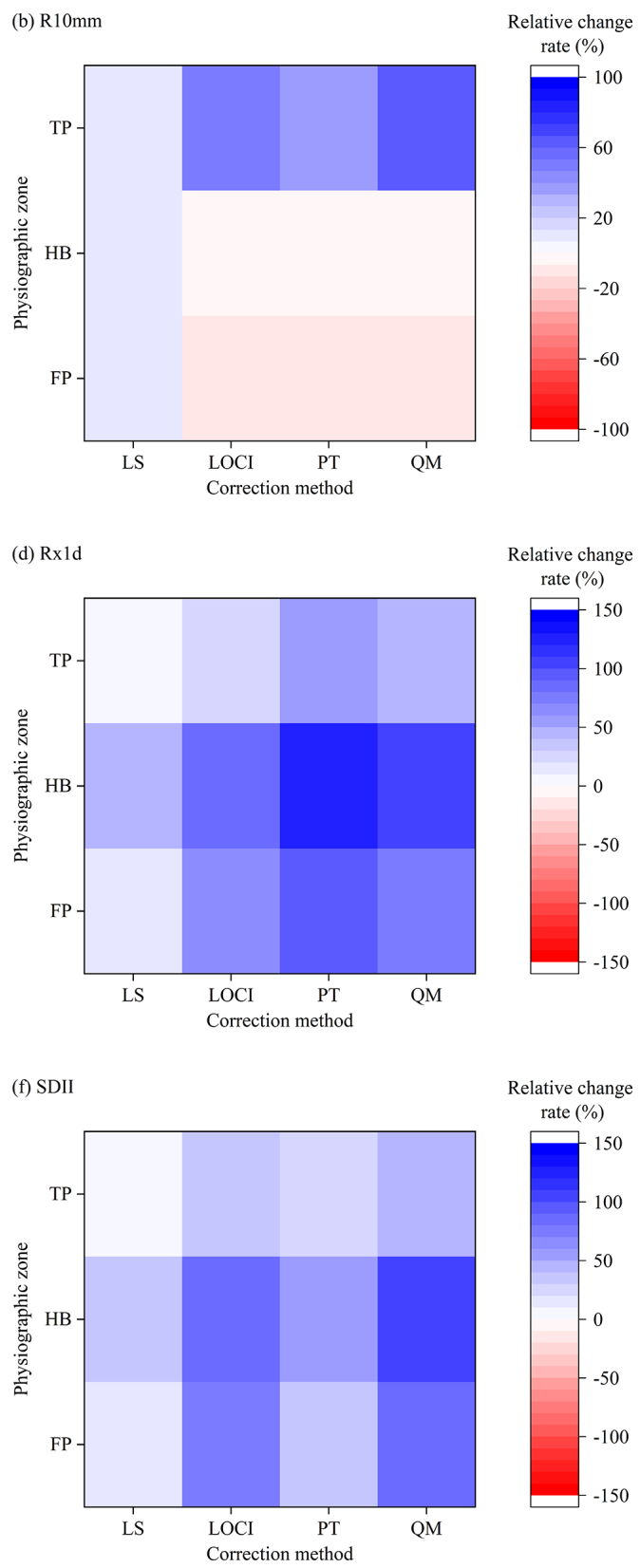

(d) Rx1d, (e) Rx5d, and (f) SDII during JJAS for the original and ing to more sophisticated nonlinear methods (Teutschbein and Seibert, 2012). Although mean precipitation corrected by all bias-corrected approaches was similar, the standard deviations and consequent extreme precipitation indices varied considerably. In the case of linear correction, both mean and standard deviation are multiplied by same factor (Leander and Buishand, 2007), resulting in dubious variations in precipitation. Nonlinear correction adjusts the mean and coefficient of variation (Teutschbein and Seibert, 2012), yielding more reliable results. In addition, the typical biases of rainfall products are related to their identification of too many 

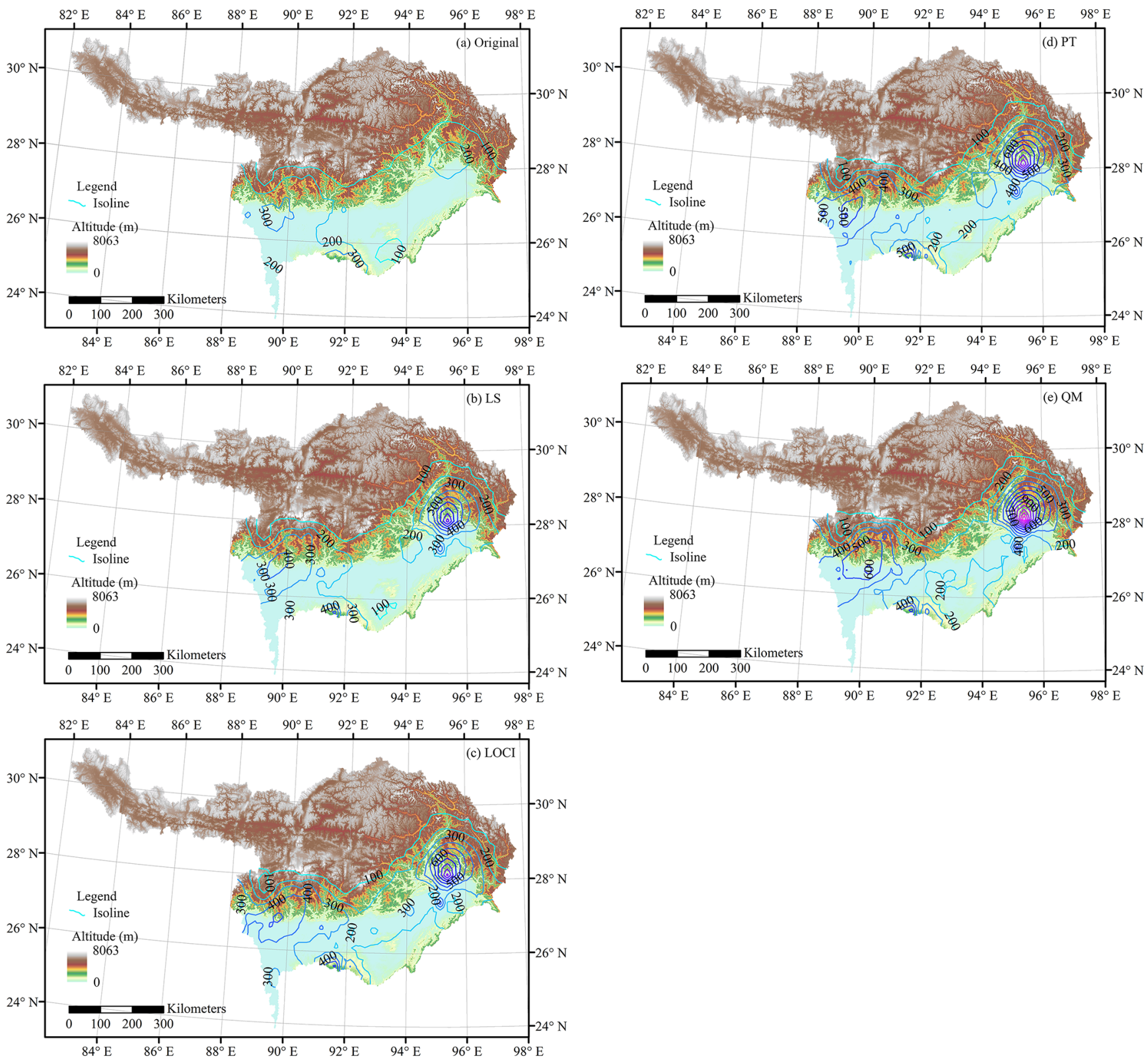

Figure 6. Spatial distribution of mean Rx5d during JJAS in the YBRB based on (a) the original APHRODITE estimates, (b) linear scaling (LS)-APHRODITE estimates, (c) local intensity scaling (LOCI)-APHRODITE estimates, (d) power transformation (PT)-APHRODITE estimates, and (e) quantile-quantile mapping (QM)-APHRODITE estimates.

wet days with low-intensity precipitation. Among the four bias-corrected approaches applied herein, LS and PT make no change to the number of rainy days, while LOCI and QM use threshold exceedance to match the wet-day frequency to the observations.

In international river basins, rainfall data are usually not publicly available, and extreme precipitation analysis may suffer from data restrictions (Nishat and Rahman, 2009; Luo et al., 2019). Several great international rivers in South Asia, including the Indus, Ganges, and Yarlung TsangpoBrahmaputra, originate from or flow through the Himalayas.
Topographic variations in the Himalayas profoundly influence the spatial distribution of precipitation by altering monsoonal flow, resulting in considerable orographic rainfall on the windward slopes (Khandu et al., 2017). Rainfall estimates of different products varied markedly along the Himalayan front and obtained similar results toward the adjacent low-relief domains (Andermann et al., 2011). The GHCN-Daily data can be applied to correct gauge-based gridded datasets in this region, ensuring these products capture the spatial distribution and variation in extreme precipitation. However, numerous GHCN-Daily records in Asia do 
not contain data from recent years, and the short or incomplete rainfall records limit their direct applications (Donat et al., 2013). Hence, it would be preferable to apply nonpublic datasets in data-sparse regions.

\section{Conclusions}

Despite increasing use of gridded rainfall products in sparsely gauged river basins, their application in extreme precipitation analysis is challenging due to considerable biases. This study made use of four methods to correct APHRODITE estimates in the YBRB. Their influences on extreme precipitation indices were compared and assessed. The following conclusions were drawn.

1. The original APHRODITE estimates tended to underestimate heavy and very heavy precipitation in the YBRB, and there were a lot of days with low precipitation estimations instead of substantial dry conditions. Bias correction greatly improved the performance of extreme precipitation analysis. The extreme precipitation indices calculated from different corrected APHRODITE estimates varied substantially, and LOCIand QM-APHRODITE estimates were able to obtain more reliable extreme precipitation indices.

2. Insufficient gauge observations in the Himalayas caused high uncertainty in the heavy precipitation estimates for the original APHRODITE estimates. After bias correction using observations from a denser network of gauges, the heterogeneous orographic effects on extreme precipitation were captured more accurately.

Data availability. The co-authors used publicly available data from the Asian Precipitation Highly Resolved Observational Data Integration Towards Evaluation of Water Resources and the National Centers for Environmental Information. In addition, rainfall observations in China were obtained from the National Meteorological Information Center (2020, http://data.cma.cn).

Author contributions. XL and YL conceived the study, XL and XF carried out bias correction and extreme precipitation analysis, $\mathrm{XL}$ drafted the paper, and all co-authors jointly worked on enriching and developing the draft.

Competing interests. The authors declare that they have no conflict of interest.

Special issue statement. This article is part of the special issue "Advances in extreme value analysis and application to natural hazards". It is not associated with a conference.
Acknowledgements. This study was supported by the National Natural Science Foundation of China (41661144044, 41601026), the National Key R\&D Program of China (2016YFA0601601), and the Science and Technology Planning Project of Yunnan Province, China (2017FB073).

Financial support. This research has been supported by the National Natural Science Foundation of China (grant nos. 41661144044 and 41601026), the National Key R\&D Program of China (grant no. 2016YFA0601601), and the Science and Technology Planning Project of Yunnan Province, China (grant no. 2017FB073).

Review statement. This paper was edited by Sylvie Parey and reviewed by Yoann Robin and one anonymous referee.

\section{References}

Alexander, L. V.: Global observed long-term changes in temperature and precipitation extremes: A review of progress and limitations in IPCC assessments and beyond, Weather. Clim. Extremes, 11, 4-16, https://doi.org/10.1016/j.wace.2015.10.007, 2016.

Andermann, C., Bonnet, S., and Gloaguen, R.: Evaluation of precipitation data sets along the Himalayan front, Geochem. Geophys. Geosys., 12, Q07023, https://doi.org/10.1029/2011gc003513, 2011.

Bookhagen, B. and Burbank, D. W.: Toward a complete Himalayan hydrological budget: Spatiotemporal distribution of snowmelt and rainfall and their impact on river discharge, J. Geophys. Res., 115, F03019, https://doi.org/10.1029/2009JF001426, 2010.

Cannon A. J., Sobie S. R., and Murdock T. Q.: Bias correction of GCM precipitation by quantile mapping: How well do methods preserve changes in quantiles and extremes?, J. Climate, 28, 6938-6959, https://doi.org/10.1175/JCLI-D-14-00754.1, 2015.

Chaudhary S., Dhanya C. T., and Vinnarasi R.: Dry and wet spell variability during monsoon in gauge-based gridded daily precipitation datasets over India, J. Hydrol., 546, 204-218, https://doi.org/10.1016/j.jhydrol.2017.01.023, 2017.

Dhar, O. N. and Nandargi, S.: A study of floods in the Brahmaputra Basin in India, Int. J. Climatol., 20, 771-781, 2000.

Dimri, A. P., Thayyen, R. J., Kibler, K., Stanton, A., Jain, S. K., Tullos, D., and Singh, V. P.: A review of atmospheric and land surface processes with emphasis on flood generation in the Southern Himalayan rivers, Sci. Total Environ., 556, 98-115, https://doi.org/10.1016/j.scitotenv.2016.02.206, 2016.

Donat, M. G., Alexander, L. V., Yang, H., Durre, I., Vose, R., and Caesar, J.: Global land-based datasets for monitoring climatic extremes, B. Am. Meteorol. Soc., 94, 997-1006, https://doi.org/10.1175/BAMS-D-12-00109.1, 2013.

Duan, Z., Liu, J., Tuo, Y., Chiogna, G., and Disse, M.: Evaluation of eight high spatial resolution gridded precipitation products in Adige Basin (Italy) at multiple temporal and spatial scales, Sci. Total Environ., 573, 1536-1553, https://doi.org/10.1016/j.scitotenv.2016.08.213, 2016. 
Easterling, D. R.: Climate extremes: observations, modeling, and impacts, Science, 289, 2068-2074, https://doi.org/10.1126/science.289.5487.2068, 2000.

Gain, A. K., Immerzeel, W. W., Sperna Weiland, F. C., and Bierkens, M. F. P.: Impact of climate change on the stream flow of the lower Brahmaputra: trends in high and low flows based on discharge-weighted ensemble modelling, Hydrol. Earth Syst. Sci., 15, 1537-1545, https://doi.org/10.5194/hess-15-1537-2011, 2011.

Guan, Z. H., Chen, C. Y., Ou, Y. X., Fan, Y. Q., Zhang, Y. S., Chen, Z. M., Bao, S. H., Zu, Y. T., He, X. W., and Zhang, M. T. (Eds.): Rivers and Lakes in Tibet, Science Press, Beijing, China, 1984.

He, Z., Hu, H., Tian F., Ni G., and Hu, Q.: Correcting the TRMM rainfall product for hydrological modelling in sparselygauged mountainous basins, Hydrolog. Sci. J., 62, 306-318, https://doi.org/10.1080/02626667.2016.1222532, 2017.

Immerzeel, W.: Historical trends and future predictions of climate variability in the Brahmaputra basin, Int. J. Climatol., 28, 243 254, https://doi.org/10.1002/joc.1528, 2008.

Immerzeel, W. W., van Beek, L. P. H., and Bierkens, M. F. P.: Climate change will affect the Asian water towers, Science, 328, 1382-1385, https://doi.org/10.1126/science.1183188, 2010.

Janes, T., Mcgrath, F., Macadam, I., and Jones, R.: High-resolution climate projections for south Asia to inform climate impacts and adaptation studies in the Ganges-Brahmaputra-Meghna and Mahanadi deltas, Sci. Total Environ., 650, 1499-1520, https://doi.org/10.1016/j.scitotenv.2018.08.376, 2019.

Kamal-Heikman, S., Derry, L. A., Stedinger, J. R., and Duncan, C. C.: A simple predictive tool for lower Brahmaputra River basin monsoon flooding, Earth Interact., 11, 1-11, https://doi.org/10.1175/EI226.1, 2007.

Khandu, Awange, J. L., Kuhn, M., Anyah, R., and Forootan, E.: Changes and variability of precipitation and temperature in the Ganges-Brahmaputra-Meghna River Basin based on global high-resolution reanalyses, Int. J. Climatol., 37, 2141-2159, https://doi.org/10.1002/joc.4842, 2017.

Lakshmi, V., Fayne, J., and Bolten, J.: A comparative study of available water in the major river basins of the world, J. Hydrol., 567, 510-532, https://doi.org/10.1016/j.jhydrol.2018.10.038, 2018.

Leander, R. and Buishand, T. A.: Resampling of regional climate model output for the simulation of extreme river flows, J. Hydrol., 332, 487-496, https://doi.org/10.1016/j.jhydrol.2006.08.006, 2007.

Lenderink, G., Buishand, A., and van Deursen, W.: Estimates of future discharges of the river Rhine using two scenario methodologies: direct versus delta approach, Hydrol. Earth Syst. Sci., 11, 1145-1159, https://doi.org/10.5194/hess-11-1145-2007, 2007.

Liu, Z., Wang, R., and Yao, Z.: Climate change and its impact on water availability of large international rivers over the mainland Southeast Asia, Hydrol. Process., 32, 3966-3977, https://doi.org/10.1002/hyp.13304, 2018.

Luo, X., Wu, W., He, D., Li, Y., and Ji, X.: Hydrological simulation using TRMM and CHIRPS precipitation estimates in the lower Lancang-Mekong River Basin, Chinese Geogr. Sci., 29, 13-25, https://doi.org/10.1007/s11769-019-1014-6, 2019.

Malik, N., Bookhagen, B., and Mucha, P. J.: Spatiotemporal patterns and trends of Indian monsoonal rainfall extremes, Geophys. Res. Lett., 43, 1710-1717, https://doi.org/10.1002/2016GL067841, 2016.
National Meteorological Information Center: Rainfall observations in China, available at: http://data.cma.cn, last access: 13 August 2020.

Nishat, B. and Rahman, S. M. M.: Water resources modeling of the Ganges-Brahmaputra-Meghna River basins using satellite remote sensing data, J. Am. Water Resour. As., 45, 1313-1327, https://doi.org/10.1111/j.1752-1688.2009.00374.x, 2009.

Pervez, M. S. and Henebry, G. M.: Spatial and seasonal responses of precipitation in the Ganges and Brahmaputra river basins to ENSO and Indian Ocean dipole modes: implications for flooding and drought, Nat. Hazards Earth Syst. Sci., 15, 147-162, https://doi.org/10.5194/nhess-15-147-2015, 2015.

Prakash, S., Mitra, A. K., Momin, I. M., Rajagopal, E. N., Basu, S., Collins, M., Turner, A. G., Rao, K. A., and Ashok, K.: Seasonal intercomparison of observational rainfall datasets over India during the southwest monsoon season, Int. J. Climatol., 35, 2326-2338, https://doi.org/10.1002/joc.4129, 2015.

Prakash, S., Seshadri, A., Srinivasan, J., and Pai, D. S.: A new parameter to assess impact of rain gauge density on uncertainty in the estimate of monthly rainfall over India, J. Hydrometeorol. 20, 821-832, https://doi.org/10.1175/JHM-D-18-0161.1, 2019.

Rana, S., McGregor, J., and Renwick, J.: Precipitation seasonality over the Indian subcontinent: an evaluation of gauge, reanalyses, and satellite retrievals, J. Hydrometeorol., 16, 631-651, https://doi.org/10.1175/jhm-d-14-0106.1, 2015.

Ray, P. A., Yang, Y. E., Wi, S., Khalil, A., Chatikavanij, V., and Brown, C.: Room for improvement: Hydroclimatic challenges to poverty-reducing development of the Brahmaputra River basin, Environ. Sci. Policy, 54, 64-80, https://doi.org/10.1016/j.envsci.2015.06.015, 2015.

Schmidli, J., Frei, C., and Vidale, P. L.: Downscaling from GCM precipitation: a benchmark for dynamical and statistical downscaling methods, Int. J. Climatol., 26, 679-689, https://doi.org/10.1002/joc.1287, 2006.

Sillmann, J., Kharin, V. V., Zhang, X., Zwiers, F. W., and Bronaugh, D.: Climate extremes indices in the CMIP5 multimodel ensemble: Part 1. Model evaluation in the present climate, J. Geophys. Res.-Atmos., 118, 1716-1733, https://doi.org/10.1002/jgrd.50203, 2013.

Singh, S., Kumar, R., Bhardwaj, A., Sam, L., Shekhar, M., Singh, A., Kumar, R., and Gupta, A.: Changing climate and glaciohydrology in Indian Himalayan Region: a review, Wires. Clim. Change, 7, 393-410, https://doi.org/10.1002/wcc.393, 2016.

Singh, V. P., Sharma, N., and Ojha, C. S. P. (Eds.): The Brahmaputra Basin water resources, Kluwer Academic Publishers, Dordrecht, Netherlands, 2004.

Teutschbein, C. and Seibert, J.: Bias correction of regional climate model simulations for hydrological climate-change impact studies: Review and evaluation of different methods, J. Hydrol., 456457, 12-29, https://doi.org/10.1016/j.jhydrol.2012.05.052, 2012.

Wang, C., Ren, X., and Li, Y.: Analysis of extreme precipitation characteristics in low mountain areas based on three-dimensional copulas-taking Kuandian County as an example, Theor. Appl. Climatol., 128, 169-179, https://doi.org/10.1007/s00704-0151692-7, 2017.

Xu, R., Hu, H., Tian, F., Li, C., and Khan, M. Y. A.: Projected climate change impacts on future streamflow of the Yarlung Tsangpo-Brahmaputra River, Global Planet. Change, 175, 144159, https://doi.org/10.1016/j.gloplacha.2019.01.012, 2019. 
Yatagai, A., Kamiguchi, K., Arakawa, O., Hamada, A., Yasutomi, N., and Kitoh, A.: APHRODITE: Constructing a long-term daily gridded precipitation dataset for Asia based on a dense network of rain gauges, B. Am. Meteorol. Soc., 93, 1401-1415, https://doi.org/10.1175/bams-d-11-00122.1, 2012.

Yucel, I. and Onen, A.: Evaluating a mesoscale atmosphere model and a satellite-based algorithm in estimating extreme rainfall events in northwestern Turkey, Nat. Hazards Earth Syst. Sci., 14, 611-624, https://doi.org/10.5194/nhess-14-611-2014, 2014.
Zhang, Y., Zheng, H., Herron, N., Liu, X., Wang, Z., Chiew, F. H. S., and Parajka, J.: A framework estimating cumulative impact of damming on downstream water availability, J. Hydrol., 575, 612-627, https://doi.org/10.1016/j.jhydrol.2019.05.061, 2019. 